\title{
Research on Ecological Compensation Standard of Dalian Jinshitan National Marine Park Based on CVM
}

\author{
Huijie Gao*
}

\author{
School of Economics and Management, Beijing Jiaotong University, China \\ ${ }^{*}$ Corresponding author. Email: 20120724@bjtu.edu.cn
}

\begin{abstract}
National marine parks play an important role in protecting the marine ecological environment and resources. Based on the related theories of welfare economics and environmental economics, taking Dalian Jinshitan National Marine Park as the research object and adopting CVM from the perspective of ecological protection and compensation, the marine park's ecological compensation standard are accounted for. Taking willingness to pay (WTP) as the ecological compensation standard of Jinshitan National Marine Park is finally determined to be 115.65yuan/year/person. Secondly, the factors that affect WTP are studied marine parks is mainly affected by gender, age, income, education level, work unit, number of trips and tourism satisfaction.
\end{abstract}

Keywords: National Marine Park, WTP, Ecological compensation standard, CVM, Dalian Jinshitan.

\section{INTRODUCTION}

The national marine park is an area that protects the marine ecological environment, allows the public to carry out appropriate recreational activities and promotes marine ecological protection and the sustainable development of coastal tourism [1]. The influx of a large number of tourists and excessive tourism development have led to an increase in marine park pollution and biodiversity destruction, which has a negative impact on the marine ecological environment and the sustainable development of tourism. Residents near the park must also give up some development opportunities to protect marine ecology, resulting in conflicts that are difficult to coordinate among relevant stakeholders. The ecological compensation system has advantages in coordinating the conflicts between relevant stakeholders and balancing tourism development and marine ecological environment protection [2]. Ecological compensation also encourages the behaviour of protecting and restoring the ecological environment and internalizes external costs and uses economic means to adjust the relationship between relevant stakeholders, so as to protect the ecological environment and promote ecological sustainable development [3].

This paper takes Jinshitan National Marine Park as the research object and applies the CVM method and conducts a quantitative study on the standard of ecological compensation for marine parks from the perspective of the willingness of ecological protection compensation. To a certain extent, it is a supplement to the research on marine ecological compensation in China and can be able to improve the research system of ecological compensation and promotes the development of national marine parks in the field of ecological compensation research.

\section{LITERATURE REVIEW}

The concept of ecological compensation is originated from ecological theory and specifically refers to natural ecological compensation. Since the 1980s, many scholars have begun to conduct extensive research on ecological compensation. However, due to different academic backgrounds, scholars have different understanding of ecological compensation so that there is no recognized concept of ecological compensation. Payment for Ecological Services (PES) is a common concept in existing foreign research, it is defined as the need to pay a certain fee for the services provided by the ecological environment and people are encouraged to protect the environment in this way.

In China, scholars use "Ecological Compensation" as a common concept. Wenhua $\mathrm{Li}$ believes that ecological compensation includes not only compensation for ecological resource protection activities or compensation for losses caused by 
ecological damage, but also fees for environmental pollution activities [4]. Fen $\mathrm{Xu}$ et al. proposed that ecological compensation is an economic measure that the government guides various stakeholders to invest in ecological environmental protection to reduce the destruction of the ecological environment [5]. Tiantian Guo believes that ecological compensation is a coordination mechanism for the purpose of ecological protection to reduce pollution and damage to the ecological environment and to compensate the main body of losses caused by environmental damage [6].

The standard of ecological compensation is the compensation to the providers and protectors of ecological environment and it is the key to the research of ecological compensation. The determination of ecological compensation standard affects the feasibility and effectiveness of the implementation of ecological compensation. However, due to the different research ideas and methods of various scholars, the estimation and calculation of ecological compensation standard have not yet been unified.

The calculation of ecological compensation standard includes ecosystem service value, willingness survey method and cost accounting algorithm, etc. Costanza evaluated the value of global ecosystem service functions for the first time and made a pioneering contribution, which promoted the development of ecosystem service value evaluation [7]. Fuguo Liu used Nanshan National Park as the research area and evaluated the three types of ecosystems in the area: forest, grassland and wetland. The service function value was used as the upper limit of the ecological compensation standard and the opportunity cost of ecological protection was used as the lower reference limit of the ecological compensation standard [8]. Aiping Zha used the zonal travel cost method (ZTCM) and the travel cost interval analysis method (TCIA) to evaluate the domestic recreational value of Hangzhou West Lake Scenic Area [9]. Taking Huangshan Scenic Area as an example, Jinhe Zhang used the conditional value method and used payment card questionnaire to investigate the willingness to pay and influencing factors of tourists [10].

At present, there are few studies on the ecological compensation standard of marine parks in China, and most of them draw on the methods of forest and watershed ecological compensation standard. There are still gaps in the ecological compensation standard of national marine parks. Finally, the study of ecological compensation standard accounting has not yet formed a unified and standardized theory and method system and it needs to be further deepened.

\section{METHODS}

\subsection{Research Area}

Dalian Jinshitan National Marine Park is located on the coast of the Yellow Sea on the Liaodong Peninsula in my country. It covers an area of 11,000 hectares with a sea area of 5140 hectares and a coastline of 30 kilometres. The scenery of Jinshitan is beautiful, the sea is not silted or frozen and it is suitable for coastal leisure activities. Jinshitan was listed as a national marine park in 2014. Jinshitan Marine Park attracts a large number of tourists every year to experience seaside leisure activities. However, the number of tourists is increasing year by year and coupled with continuous development and utilization, which has a certain impact on its ecological environment, such as water pollution and vegetation destruction.

\subsection{Methodology}

Conditional Value Method (CVM), as a method of stated preference, is mainly used to assess the nonmarket value of public goods and is currently widely used. In 1963, Davis first used CVM to evaluate the recreational value of forests [11]. Since then, CVM has been more and more widely used to assess the value of land resources, water resources and tourism resources. Hailing Guan took Wutaishan National Forest Park as an example and used CVM method to evaluate its ecosystem service function [12]. Zhuquan Yang applied CVM to investigate the willingness to pay in Yangshuo County, Guilin and used non-parametric estimation and multiple linear regression estimation methods to measure tourist ecological compensation [13]. Aiping Zha used the double-bounded dichotomous choice CVM to evaluate the non-use value of West Lake tourism resources [14].

CVM is the only method that can evaluate non-use value and estimate the total economic value [15]. In addition, most of the ecological compensation policies implemented in our country are led by the government. This method is used to investigate willingness to pay (WTP), taking into account the ideas of other stakeholders and emphasizing the participation of the public, which is conducive to improving public's enthusiasm and acceptance of ecological compensation and promote better implementation of ecological compensation [16].

\subsection{Data Collection}

This paper adopts a payment card questionnaire to provide respondents with a series of orderly payment prices and guide respondents to choose payment prices according to their own wishes. The questionnaire is divided into three parts. The first part introduces the purpose of the survey and the concept of ecological 
compensation and the background information of Dalian Jinshitan National Marine Park to the interviewees. The second part is the core part of the questionnaire. The payment card questionnaire is used to ask tourists and residents' WTP for marine ecosystem services, payment methods and reasons for unwillingness to pay. The third part includes the personal characteristics of the interviewees, the number of trips, the degree of awareness of ecological compensation and the satisfaction with the Jinshitan ecological environment and tourism experience.

Before the formal survey, in order to ensure that the questionnaire is scientific and reasonable, 100 questionnaires were distributed on the online platform for pre-survey and the questionnaire was finally designed after continuous modification. This study conducted a random sampling survey from April 2nd to April 25th, 2020. Take the form of online survey and publish the questionnaire on the online platform. A total of 400 questionnaires were distributed in this survey and 42 invalid questionnaires were eliminated. 358 people were willing to pay.

\section{RESULTS}

\subsection{Demographic Analysis}

The socio-economic characteristics of the samples are analysed by SPSS 26.0. Among the 358 respondents in this survey, men accounted for $49.1 \%$ of the total sample; women accounted for $50.9 \%$ and the overall proportion showed a balanced structure. In terms of age, the samples were mostly under 35 years old, accounting for $74.6 \%$; respondents aged $36-55$ accounted for $20.4 \%$ and samples over 55 years old accounted for $5 \%$. In terms of education level, the respondents generally have a higher level of education. Most of the interviewees' income is more than 60,000 yuan, accounting for $55.6 \%$ of the overall sample. Enterprise employees account for the majority of respondents and their work units are state-owned enterprises, the number of foreign-funded enterprises and private enterprises accounted for $52.3 \%$ and the number of employees working for environmental protection organizations was the least, only $0.9 \%$. In terms of the place of origin of the interviewees, more than $70 \%$ are from outside Dalian and the interviewees are mainly concentrated in the three northeast provinces and other surrounding provinces. Regarding the number of trips to Jinshitan, more than $55 \%$ of tourists visited Jinshitan once. $11.2 \%$ of the respondents have visited more than 3 times and most of them are from Dalian, as shown in Table 1.

According to the survey, $31.8 \%$ of the interviewees said they did not know much about ecological compensation and $38.4 \%$ of the interviewees said that they had a fair understanding of ecological compensation which means they are not familiar with the concept of ecological compensation and related

Table 1 Variable coding and demographic analysis

\begin{tabular}{|c|c|c|c|c|}
\hline Variables & Code & Meanings & Ave & $\mathrm{SD}$ \\
\hline Gender & GEN & Male $=1 ;$ Female $=2$ & 1.51 & 0.501 \\
\hline Age & AGE & $18-25$ years old $=1 ; 26-35$ years old $=2 ; 36-55$ years old $=3 ;$ Over 55 years old $=4 ;$ & 2.00 & 0.839 \\
\hline Education level & EDU & $\begin{array}{l}\text { High school and below }=1 ; \text { Post-secondary }=2 ; \text { Undergraduate }=3 ; \text { Master degree } \\
\text { and above }=4\end{array}$ & 2.65 & 1.676 \\
\hline Annual income & INC & $\begin{array}{l}\text { Less than } 20,000=1 ; 20,000-40,000=2 ; 40,000-60,000=3 ; 60,000- \\
\qquad 80,000=4 ; 80,000-100,000=5 ; \text { More than } 100,000=6\end{array}$ & 3.65 & 0.823 \\
\hline Work unit & WU & $\begin{array}{c}\text { Government }=1 ; \text { School=2;State-owned enterprise }=3 ; \text { Institutions }=4 ; \text { Foreign } \\
\text { company }=5 ; \text { Private enterprise }=6 ; \text { Farmer }=7 ; \text { Environmental organizations }=8 ;\end{array}$ & 3.92 & 1.963 \\
\hline $\begin{array}{l}\text { Permanent } \\
\text { residence }\end{array}$ & PR & In Dalian city $=1 ;$ Outside Dalian city $=2$ & 1.73 & 0.444 \\
\hline Number of trips & NOT & Once $=1 ;$ Twice $=2 ;$ Three times and above $=3$ & 1.62 & 0.766 \\
\hline $\begin{array}{l}\text { Understanding of } \\
\text { ecological } \\
\text { compensation }\end{array}$ & UEC & $\begin{array}{l}\text { Not understand very well }=1 ; \text { Not understand }=2 ; \text { Fair }=3 ; \text { Understand }=4 ; \text { Understand } \\
\text { very well }=5\end{array}$ & 2.91 & 0.978 \\
\hline Propaganda power & PRO & Very weak $=1 ;$ Week $=2 ;$ Fair $=3 ;$ Strong $=4 ;$ Very strong $=5$ & 3.00 & 1.008 \\
\hline $\begin{array}{l}\text { Satisfaction of } \\
\text { ecological } \\
\text { environment }\end{array}$ & SEE & Very dissatisfied $=1 ;$ Dissatisfied $=2 ;$ Fair $=3 ;$ Satisfied $=4 ;$ Very satisfied $=5$ & 3.50 & 0.828 \\
\hline $\begin{array}{c}\text { Tourism } \\
\text { satisfaction }\end{array}$ & TS & Very dissatisfied $=1 ;$ Dissatisfied $=2 ;$ Fair $=3 ;$ Satisfied $=4 ;$ Very satisfied $=5$ & 3.61 & 0.821 \\
\hline
\end{tabular}


policies. By asking the interviewees about the government's current propaganda efforts on ecological compensation, it was learned that nearly $70 \%$ of the interviewees believed that the Chinese government's propaganda efforts on ecological compensation were average or below, indicating that local governments have not started the popularization of ecological compensation. In terms of ecological environment satisfaction, $11.6 \%$ of the respondents said they were dissatisfied with the ecological environment of Jinshitan, $35.6 \%$ said the ecological environment was fair and $52.8 \%$ of the respondents said they were satisfied with the ecological environment. Regarding the tourism satisfaction of Jinshitan, $8.7 \%$ of the respondents were dissatisfied, $31.6 \%$ thought it was fair, and the remaining $59.7 \%$ were satisfied with the Jinshitan tourism experience.

\subsection{Analysis of WTP}

In the 358 questionnaires surveyed on WTP, the number of people who chose to pay 0 yuan accounted for $5.6 \%$. The remaining nearly $95 \%$ of the interviewees are willing to pay for the protection of the ecological environment, which fully shows that people have a strong concern for ecological protection. Respondents' willingness to pay are mainly distributed in bid values of 100 yuan, 50 yuan, 200 yuan, 20 yuan and 10 yuan. About $2-3 \%$ of the people who choose 501 yuan and above account for about $2-3 \%$, of which the largest bid value is 1000 yuan, as shown in Figure 1.

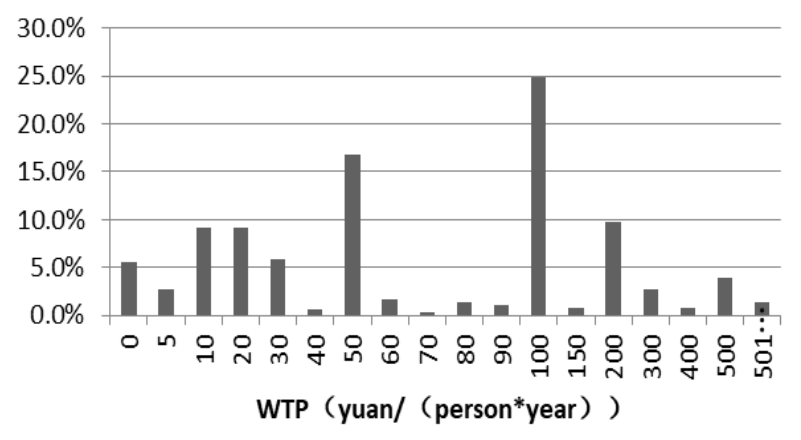

Figure 1 Proportion of WTP.

Regarding the donation methods of environmental protection funds, $57.5 \%$ of the respondents choose to donate to foundations or environmental protection organizations. $16.2 \%$ choose to pay for the funds through taxation and $21.5 \%$ hope to increase the ticket price for ecological compensation. The remaining $0.8 \%$ chose other methods, such as donating directly on the official website and directly donating the funds to the person in charge of the local management agency.

The main reason why respondents who choose 0 yuan is that they worry that the payment amount will not be used for ecological protection, accounting for $33.3 \%$ of the total, which also reflects people's distrust of environmental protection agencies. $22.2 \%$ of people said that ecological compensation is the main responsibility of the government for ecological compensation funds. $16.7 \%$ of respondents are unwilling to pay because of their low income and inability. $16.7 \%$ of respondents said they have already paid tickets to the park. $8.3 \%$ of the interviewees believe that this is the responsibility of the ecological environment destroyer. $2.8 \%$ believe that this is the responsibility of the local residents of Dalian and has nothing to do with them.

\subsection{Nonparametric Estimation of WTP}

In this paper, the nonparametric estimation method is used to calculate the WTP of Jinshitan marine ecosystem services. This method directly uses the average value to estimate the willingness to pay and obtains the result by calculating the product of each bid value and its probability. The expected value of WTP is calculated using Equation (1):

$E(W T P)=\sum_{i=1}^{n} P_{i} * A_{i}$

In the formula: Ai represents the ith bid value of the willingness to pay selected by the respondent; $\mathrm{Pi}$ represents the probability that the respondent chooses the ith bid value.

Putting the value into Equation (1), the per capita annual WTP is obtained. Therefore, the ecological compensation standard of Jinshitan National Marine Park is determined to be 115.65 yuan/year/person.

\subsection{Analysis of Influencing Factors of WTP}

The factors influencing WTP are studied through multiple linear regression models. Respondents will be affected by subjective and objective factors when choosing bid values, such as gender, age, annual income. This article takes the WTP as the dependent variable and the respondent's socio-economic attributes, the degree of understanding of Jinshitan, the government's promotion of ecological compensation and tourism satisfaction as independent variables. Constructing the logarithmic linear regression model of WTP for marine park ecological compensation standard, as shown in Equation (2).

$\operatorname{Ln} Y=\beta_{0}+\beta_{1} X_{1}+\beta_{2} X_{2}+\beta_{3} X_{3}+\cdots+\beta_{i} X_{i}+\mu$ (2)

In the formula: $\mathrm{Y}$ is the WTP of the surveyed person; $\mathrm{X} 1, \mathrm{X} 2, \mathrm{X} 3 \ldots$ are the characteristic attributes of the surveyed person; $\mu$ is the random error term.

Before regression analysis, the independent variables are processed first. Because there are categorical variables in the independent variables, the categorical variables are converted into dummy variables and substituted into the model. Gender is referenced to 
females; academic qualifications are referenced to high school and below; work units are referenced to government; permanent residence is referenced to in Dalian City and the number of trips is referenced to once. Age and income are treated as continuous variables with the median value of the interval and other numerical independent variables.

The research uses SPSS26.0 software to conduct multiple linear regression analysis on the WTP for ecological compensation in the Jinshitan National Marine Park and uses OLS to estimate the relationship between the WTP and other variables.

The results show that the main factors affecting the WTP are gender, age, income, education level, travel times, work unit and tourism satisfaction. The regression results are shown in Table 2. After removing insignificant variables, the regression model of WTP is finally obtained, which is shown in Equation (3).

$$
\begin{aligned}
\text { LnWTP }= & 2.767+0.269 G E N-0.023 A G E+ \\
& 0.067 I N C+0.462 E D U 1+0.746 E D U 2+ \\
& 0.913 E D U 3-0.463 W U 2+ \\
& 0.507 N O T 1+0.717 N O T 2+0.315 T S \text { (3) }
\end{aligned}
$$

Respondents' WTP is significantly positively correlated with gender and men's WTP is higher than women's. There is a significant positive correlation between income and WTP. The higher the income, the higher the WTP for Marine Park. There is a significant positive correlation between academic qualifications and WTP. Compared with people with a high school degree or below, those with a post-secondary, undergraduate and master's degree or above are more willing to pay funds. This is because the higher the level of education, the more extensive the knowledge and the stronger the ability to accept new things. There is a significant positive correlation between the number of trips and WTP and the regression coefficient of three times or more times is greater than the regression coefficient of twice, indicating that the more trips, the more willing to pay for the protection of National Marine Park. The reason may be tourists who visit Jinshitan more often are more satisfied with the ecological environment, so they are more willing to pay ecological compensation funds. Respondents' tourism satisfaction and WTP are significantly positively correlated. The higher the travel satisfaction, the greater the willingness to pay value.

There is a significant negative correlation between age and WTP. The younger the age, the stronger the WTP. Compared with elder people, young people have stronger acceptance of environmental protection concepts, higher environmental awareness and willingness to participate in ecological protection actions. In terms of work unit, compared with the willingness to pay of respondents who work in the government, respondents whose work units are stateowned enterprises are less willing to pay ecological compensation.

\section{CONCLUSIONS}

National Marine Parks play an important role in protecting the marine ecological environment. However, due to excessive tourism development activities, the marine ecological environment is gradually destroyed and the conflicts among stakeholders have intensified. Ecological compensation is related to protecting the marine ecological environment and regulating interests. At present, China's research on ecological compensation in marine parks is almost blank. The determination of the marine park ecological compensation standard is the core of the marine ecological compensation mechanism and determines the effect and feasibility of the marine ecological compensation. This paper takes Dalian Jinshitan National Marine Park as the research object, adopts the conditional value method to calculate the standard of marine park ecological compensation and hopes to supplement and perfect the research system of Chinese national marine park ecological compensation.

Table 2 Multiple linear regression analysis

\begin{tabular}{|l|l|l|l|l|l|}
\hline Variables & Coefficient & Sig & Variables & Coefficient & Sig \\
\hline C & 2.767 & 0.000 & WU 5 & -0.257 & 0.240 \\
\hline GEN & 0.269 & $0.022^{*}$ & WU 6 & -0.007 & 0.992 \\
\hline AGE & -0.023 & $0.001^{* *}$ & WU 7 & -0.301 & 0.782 \\
\hline INC & 0.067 & $0.003^{* *}$ & PR & -0.127 & 0.511 \\
\hline EDU 1 & 0.462 & $0.027^{*}$ & NOT 1 & 0.507 & $0.000^{* *}$ \\
\hline EDU 2 & 0.746 & $0.000^{* *}$ & NOT 2 & 0.717 & $0.001^{* *}$ \\
\hline EDU 3 & 0.913 & $0.000^{* *}$ & UEC & 0.086 & 0.220 \\
\hline WU1 & -0.223 & 0.385 & PRO & 0.113 & 0.073 \\
\hline WU 2 & -0.463 & $0.045^{* *}$ & ECS & -0.084 & 0.335 \\
\hline WU 3 & -0.373 & 0.131 & TRS & 0.315 & $0.001^{* *}$ \\
\hline WU 4 & -0.500 & 0.058 & & & \\
\hline Adjust R2 & 0.248 & & & & \\
\hline
\end{tabular}

(PS: '*’, ‘**' express as $5 \%$ and $1 \%$ significance levels respectively

In this study, the conditional value method (CVM) was used to conduct a questionnaire survey on the willingness to pay of tourists and residents of Dalian Jinshitan National Marine Park. 358 valid samples of 
willingness to pay and 66 valid samples of willingness to accept were selected. The parameter estimation method estimates that WTP for ecological compensation is 115.65 yuan/year/person. Finally, it is concluded that the ecological compensation standard of Jinshitan National Marine Park is 115.65 yuan/year/person. At the same time, multiple linear regression methods are used to construct the model and it is concluded that the main factors affecting WTP are gender, age, income, education level, work unit, number of trips and tourism satisfaction. This study selects payment card guidance technology, but the guidance technology of CVM is diverse, such as dichotomy, open type, etc. Each has its advantages and disadvantages. In future research, suitable guidance methods can be selected according to the actual situation. At the same time, there are many ecological compensation calculation methods, which one is the most reasonable is the direction that should be further studied in the future.

\section{REFERENCES}

[1] Li Yuezheng, Wangheng. National Marine Park: Concept, Features and Construction [J]. Tourism Tribune, 2015, 6 (30):11-14.

[2] Chen Haiying. Research on the Operation Mechanism and Realization Path of Tourism Ecological Compensation in Nature Reserve [D]. Yun Nan: Yunnan University, 2016.

[3] Jiang Yiyi, Song Ziqian, Zhang Min. Reflections on the Role of Tourism in the Ecological Protection Based on Research of Ecological Compensation Standard: A Case Study of Yulong Country, Yunnan Province [J]. Human Geography, 2014, 5: $149-154$

[4] Li Wenhua, Liu Moucheng. Several Strategic Thoughts on China's Eco-compensation Mechanism [J]. Resources Science, 2010, 32 (5): 791-796.

[5] Xu Fen, Shi Baoguo. Ecological Compensation - Summary of Viewpoints and Rational Choice [J], Research on Development, 2010, 5: 105-110.

[6] Guo Tiantian, Liu Dong. Research on Establishing Ecological Compensation Mechanism for Tourism Development [J]. Journal of Management, 2011, 24(3): 65-67.

[7] COSTANZA R. The Value of the World's Ecosystem Services and Natural Capital [J]. Nature, 1997, 387 (6630): 253-260.

[8] Liu Fu Guo, Li Jiao, Wang Jie, Zhang Can Ming. Research on Ecological Compensation Standard of Nanshan National Park_-Based on Ecosystem
Service Value and Opportunity Cost [J]. Hunan Forestry Science \& Technology, 2019, 46 (5): 9-16.

[9] Zha Aiping, Qiu Jiewei. Recreational Value Assessment on Hangzhou West Lake Scenic Area Based on Travel Cost [J]. Tourism Science, 2015, 29 (5): 39-50.

[10] Hu Huan, Zhang Jinhe, Liu Zehua, et al. Tourists' Willingness to Pay for Tourism Ecological Compensation and the Influencing Factors in National Parks: Take a Case of Huangshan Scenic Area [J]. Resources and Environment in the Yangtze Basin, 2017, 26 (12): 2012-2022.

[11]DAVIS R K. Recreation Planning as an Economic Problem [J]. Natural Resources Journal, 1963, 3 (2): 239-249.

[12] Guan Hailing, Liang Zhe. Research of Forest Tourism Resources in Shanxi Province Ecological Compensation Based on CVM: Wutai Mountain National Forest Park [J]. On Economic Problems, 2016, 10: 105-109.

[13] Yang Zhuquan. Research on Tourism Ecological Compensation Based on Tourists' Willingness to Pay_-Taking Yangshuo County of Guilin City as an Example [J]. Academic Forum, 2015, 5: 64-69.

[14]Zha Aiping, Qiu Jiewei, Hou Zhigang. Non-use value assessment of tourism resource based on double bound dichotomous choice contingent valuation method for Hangzhou West Lake Beauty Spot [J]. Ecological Science, 2017, 36 (2): 135-143.

[15] Guo Jiang, Li Guoping. A Review of the Key Technologies of Using CVM to Value Ecological Environment [J]. Ecological Economy, 2017, 33 (6): 115-119+126.

[16] Huo Yiyuan. A Review of Research on Ecological Compensation Standard [J]. Journal of Shaanxi University of Technology (Social Sciences), 2019, 37 (5): 25-30. 